\title{
Guidelines for Application of Central Venous Catheters in Pediatric ICU of Assiut University Children Hospital (Clinical Audit)
}

\author{
MAHER M. AHMED, M.D.; ISMAIL L. MOHAMAD, M.D. and HEBA M. AHMED, M.Sc. \\ The Department of Pediatrics, Faculty of Medicine, Assiut University, Egypt
}

\begin{abstract}
Background: Central venous catheterization can be lifesaving but is associated with complication rates of approximately $26.2 \%$. Operator experience, familiarity with the advantages and disadvantages of the various catheterization sites, and strict attention to detail during insertion help in reducing mechanical complications associated with catheterization.
\end{abstract}

Aim of Study: Evaluation of health care providers compliance to guidelines of application of CVL (central lineassociated blood stream infection (CLABSI) guidelines 2013) in PICU (Assuit University Children Hospital).

Patients and Methods: The study was conducted on patients $1 \mathrm{~m}$ to 17 years of age for whom CVCs was applied on attending Assuit University Children Hospital in PICU. The study included 80 cases during aperiod of one year from $1 / 9 / 2016$ till 1/9/2017. The study data were collected by using checklist and observing health care provider compliance to guidelines of application of CVL.

Results: Central venous catheterization can be lifesaving but is associated with complication rates of approximately $26.2 \%$ and the main indication for CVC application was shock $56.6 \%$ and stick of application of guidlines ranged between $65 \%-100 \%$.

Conclusion: We need to stick with the international guidelines as a reference standard and proper catheter maintenance care to decrease the frequency of complication mainly displacement and catheter-related infections.

Key Words: CVCs - Indications - Complications-Application

\section{Introduction}

CENTRAL venous access is defined as insertion of catheter into the venous great vessels. The venous great vessels include the superior vena cava, inferior vena cava, brachiocephalic veins, internal jugular veins, subclavian veins, iliac veins, and common femoral veins. Catheters that terminate in a systemic artery are excluded [1]

Correspondence to: Dr. Heba M. Ahmed, E-Mail: heba28590@gmail.com
The earliest pioneers of central venous catheterization in humans were Werner Forssmann, André Cournand and Dickinson Richards who jointly shared the 1956 Nobel Prize for Medicine. The first to report the use of a catheter in humans for obtaining mixed venous blood for the measurement of right atrial pressure or cardiac output were Cournand and Ranges (1941). They mentioned Forssmann (1929) as the originator of central venous catheterisation technique [2]

The line can be left in for weeks, months or years. In order for it to last as long as possible, it is important to understand what a catheter is, what it is used for and how to take care of it. With advancing paediatric healthcare, the use of central venous lines has become a fundamental part of management of neonates and children. Uses include haemodynamic monitoring and the delivery of lifesaving treatments such as intravenous fluids, blood products, antibiotics, chemotherapy, haemodialysis and total parenteral nutrition.

There are common types of central venous catheter as nontunneled CVCs implantable ports, tunneled CVCs, peripherally inserted central catheter. Central line infections in children are associated with increased mortality, increased length of hospital and intensive care unit stay, treatment interruptions, and increased complications. Prevention is paramount, using a variety of measures including tunnelling of long-term devices, chlorhexidine antisepsis, maximum sterile barriers, aseptic non-touch technique, minimal line accessing, and evidence-based care bundles [3] .

\footnotetext{
Abbreviations

CVCs : Central Venous Catheters.

PICU : Pediatric Intensive Care Unit.

CLABSI : Central Line-Associated Blood Stream Infection.
} 


\section{Patients and Methods}

Type of the study: Prospective randomized study over 1 year from Sept. 2016 - Sept. 2017.

Study setting: On PICU at Assiut University Children Hospital.

Study subjects:

A- Inclusion criteria: All patients from 1 month to 17 years of age in whom CVCs were applied.

$B$ - Exclusion criteria:

- Local infection.

- Distorted local anatomy.

- Coagulopathy.

- Previous radiation therapy.

- Suspected proximal vascular injury.

\section{Results}

The study was conducted on patient from $1 \mathrm{~m}$ to 17 years of age for whom CVCs were applied on attending Assuit University Children Hospital in PICU during period of one year from 1/9/2016 till 1/9/2017. The study included 80 cases $66.3 \%$ were males, $33.7 \%$ were females.

Table (1): Shows the demographic data of studied cases and revealed that $66.3 \%$ were males, $33.7 \%$ were females. According to the distribution of age the majority of cases were in the age range 1 day- 1 years by $43.7 \%$ followed by the age range 1 year-6 years $35 \%$, lastly $6-17$ years $21.3 \%$ each respectively.

Table (2): Shows indications of application of CVCs in studied cases and revealed that: The main indications were shock (56.2\%), lack of peripheral venous access (30\%), hypoglycemia (5\%), support of frequent blood sampling (3.8\%), then plasmapharesis and burn equally $(2.5 \%)$.

Fig. (1): Shows percentage of complications of application of CVCs in studied cases and revealed that: Complication presented only in $26.2 \%$.

Table (3): Shows types of complications of CVCs in studied cases and revealed that: Complications presented only in 21 case.

Complication related to maneuver pneumothorax and hemothorax were equally $9.5 \%$.

\section{Complication after application of CVCS:}

Main complication were misplacement $28.6 \%$, infection $23.8 \%$, then occlusion and hematoma was equally $14.3 \%$.
Table (4): Shows evaluation of guidelines of application of CVCs in studied cases and revealed that: Hand hygiene was ideally done in $93.7 \%$ and not ideally done in $6.3 \%$. Personal protective equipment was done in $75 \%$ and not done in $25 \%$.

Sterile towels use done in $65 \%$ and not done in $35 \%$. Skin antiseptsis was done ideally $95 \%$ and not ideally done (by alcohol only) in 5\%. Optimal catheter type selection was done $100 \%$. Optimal catheter site selection was done in $87.5 \%$ and not done in $12.5 \%$. Sterile dressing was done perfectly in $88.7 \%$ and was not perfectly handling in $11.3 \%$. Daily review of line necessity, with prompt removal of unnecessary CVCs was done in $86.3 \%$ and not done in $13.7 \%$.

Table (5): Shows evaluation of maintenance care of CVCs in the studied cases and revealed that: Daily dressing, site assessment was performed in $85 \%$ while not performed $15 \%$. Catheter entries care was done $60 \%$ while not done in $40 \%$. Cap/ tubing/dressing/needle changes was done by using cap of double valve way in $62.5 \%$ while not in $37.5 \%$. Catheter site care was done ideally in $85 \%$ while not ideally done in $15 \%$. Catheter hub/cap/ tubing care was done in $67.55 \%$ while not done in $32.5 \%$.

Table (1): Demographic data of studied cases.

\begin{tabular}{lll}
\hline Variable & No. & $\%$ \\
\hline Total number of cases & 80 & 100 \\
Age: & \multicolumn{2}{c}{} \\
Range & 33 day-17 year \\
(a) $1-<12$ (month) & 35 & 43.7 \\
(b) 1-<6 (year) & 28 & 35 \\
(c) 6-17 (year) & 17 & 21.3 \\
Sex: & & \\
Male & 53 & 66.3 \\
Female & 27 & 33.7 \\
\hline
\end{tabular}

Table (2): Indications of application of central venous catheters in studied cases.

\begin{tabular}{lll}
\hline Variable & No. & $\%$ \\
\hline Total number of cases & 80 & 100 \\
Lack of peripheral venous access & 24 & 30 \\
Shock & 45 & 56.2 \\
Plasmapheresis & 2 & 2.5 \\
Burn & 2 & 2.5 \\
Hypoglycemia & 4 & 5 \\
Support frequent blood sampling & 3 & 3.8 \\
\hline
\end{tabular}


Table (3): Types of complications of central venous catheter in studied cases.

\begin{tabular}{lcc}
\hline Variable & No. & $\%$ \\
\hline Number of complicated cases & 21 & 100 \\
Complication related to maneuver: & & \\
$\quad$ Pneumothorax & 2 & 9.5 \\
$\quad$ Hemothorax & 2 & 9.5 \\
Complication after application of CVCS: & & \\
$\quad$ Infection & 5 & 23.8 \\
Misplacement & 6 & 28.6 \\
Hematoma & 3 & 14.3 \\
Occlusion & 3 & 14.3 \\
\hline
\end{tabular}

Table (4): Evaluation of application of guidelines of application of central venous catheters in studied cases.

\begin{tabular}{|c|c|c|}
\hline Variable & No. & $\%$ \\
\hline Total number of cases & 80 & 100 \\
\hline \multicolumn{3}{|l|}{ Hand hygiene: } \\
\hline Done & 75 & 93.7 \\
\hline Not done & 5 & 6.3 \\
\hline \multicolumn{3}{|l|}{ Personal protective equipment: } \\
\hline Done & 60 & 75 \\
\hline Not done & 20 & 25 \\
\hline \multicolumn{3}{|l|}{ Sterile towels use: } \\
\hline Done & 52 & 65 \\
\hline Not done & 28 & 35 \\
\hline \multicolumn{3}{|l|}{ Skin antiseptsis: } \\
\hline Done (ideally) & 76 & 95 \\
\hline Not done (ideally) Alcohol only & 4 & 5 \\
\hline \multicolumn{3}{|l|}{ Optimal catheter type selection: } \\
\hline Done & 80 & 100 \\
\hline Not done & 0 & 0 \\
\hline \multicolumn{3}{|l|}{ Optimal catheter site selection: } \\
\hline Done & 70 & 87.5 \\
\hline Not done & 10 & 12.5 \\
\hline \multicolumn{3}{|l|}{ Sterile dressing: } \\
\hline Done & 71 & 88.7 \\
\hline Not done (no perfect handling) & 9 & 11.3 \\
\hline \multicolumn{3}{|c|}{$\begin{array}{l}\text { Daily review of line necessity, with prompt } \\
\text { removal of unnecessary CVCs: }\end{array}$} \\
\hline Done & 69 & 86.3 \\
\hline Not done & 11 & 13.7 \\
\hline
\end{tabular}

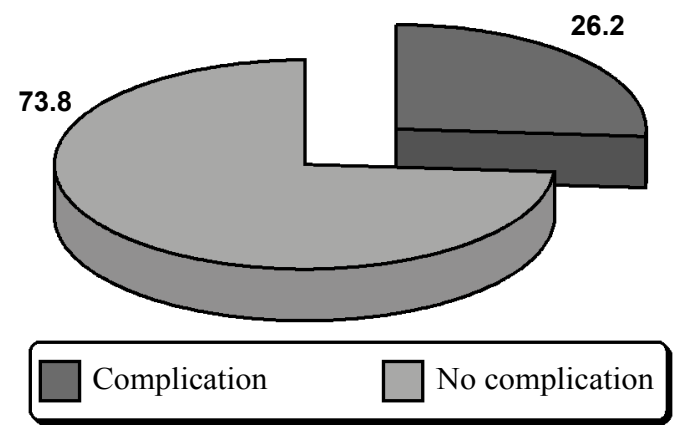

Fig. (1): Percentage of complications of application of central venous catheter in studied cases.
Table (5): Evaluation of maintenance care of central venous catheter in studied cases.

\begin{tabular}{lcc}
\hline Variable & No. & $\%$ \\
\hline Daily dressing, site assessment performed: & & \\
$\quad$ Done & 68 & 85 \\
$\quad$ Not done & 12 & 15 \\
Catheter entries care: & & \\
$\quad$ Done & 48 & 60 \\
$\quad$ Not done & 32 & 40 \\
Cap/tubing/dressing/needle changes: & & \\
$\quad$ Done (using cap of double valve way) & 50 & 62.5 \\
$\quad$ Not done & 30 & 37.5 \\
Catheter site care: & & \\
$\quad$ Done (ideally) & 68 & 85 \\
$\quad$ Not done (not ideally ) & 12 & 15 \\
Cathter hub/cap/tubing care: & & \\
$\quad$ Done & 54 & 67.5 \\
$\quad$ Not done & 26 & 32.5 \\
\hline
\end{tabular}

\section{Discussion}

Our study included 80 cases who used non tunneled central venous catheter type which is the only available type of CVCs in our PICU.

Our study included, 53 males $(66.3 \%)$ and 27 females $(33.7 \%)$. Which is similar to a results obtained by Cruzeiro et al., who started a similar study and found that $58.7 \%$ were males and $41.3 \%$ were females [4].

According to the distribution of age the majority of cases $43.7 \%$ were in the age range 1 day to 1 years followed by the age range 1 year to 6 years (35\%), lastly 6-17 years $21.3 \%$. Which nearly comes in accordance to the study done by Cruzeiro et al., [4].

According to indications of application of CVCs in the studied cases the results are in agreement with Smith et al., [5].

According to complication of application of CVCs in our studied cases.

This was nearly similar to results obtained by Eisen et al., [6].

In our study guidelines of application of central venous catheters in studied cases and maintenance care applied accordingly to central line-associated blood stream infection (CLABSI) guidelines 2013 ranged between $65-100 \%$.

\section{Conclusion:}

Appropriate catheter and site selection, sufficient operator experience, careful technique, and 
proper catheter maintenance with removal as soon as possible are associated with optimal outcome.

\section{Recommendations:}

- Hand hygiene should be done ideally according to the guidelines.

- Personal protective equipment must be used whatever the cause to prevent infection.

- Sterile towel use should be main part of sterilization system.

- Routine use of skin anti septic and not replaced by alcohol cholorohexidin is better according to our result so now it's used in our PICU.

- Daily follow-up of inserted CVCs for early detection of unnecessary or infected one.

- Early detection of CVCs infection and early treatment.

- Proper selection of the site to avoid complication during application of CVCs.

- Accurate calculation of length to avoid misplacement of CVCs.

\section{Recommendation for paramedical:}

- Sterile dressing should be handled perfectly to avoid infection.
- Daily dressing, site assessment should performed routinely.

- Catheter entries care should done daily.

- Catheter site care should be ideally done.

- Catheter hub, cap, tubing care should be done daily, flushing solution and anticoagulant daily to avoid occlusion.

\section{References}

1- STEPHEN M.R., SEATTLE W., JEFFREY L., et al.: Wilmette, Illinois, October 20, 2011.

2- FORSSMANN W.: Die Sondierung Des Rechten Herzens. Klinische Wochenschrift, 8: 2085, 1929.

3- CHESSHYRE, EMILY, et al.: "The prevention, diagnosis and management of central venous line infections in children". Journal of Infection, 71: S59-S75, 2015.

4- CRUZEIRO P., CUSTODIO F., PAULO AUGUSTO M.C. and MARCELO E.M.: "Central venous catheter placement in children: A prospective study of complications in a Brazilian public hospital". Pediatric Surgery International, 22.6: 536-40, 2006.

5- SMITH R.N. and JERRY P.N.: "Central venous catheters". " B.M.J., 347: f6570, 2013.

6- EISEN L.A., et al.: "Mechanical complications of central venous catheters". Journal of Intensive Care Medicine, 21.1: 40-6, 2006.

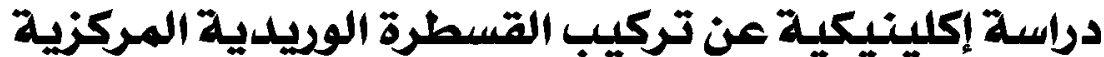

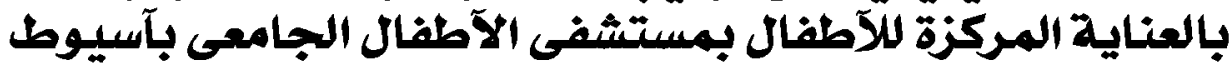

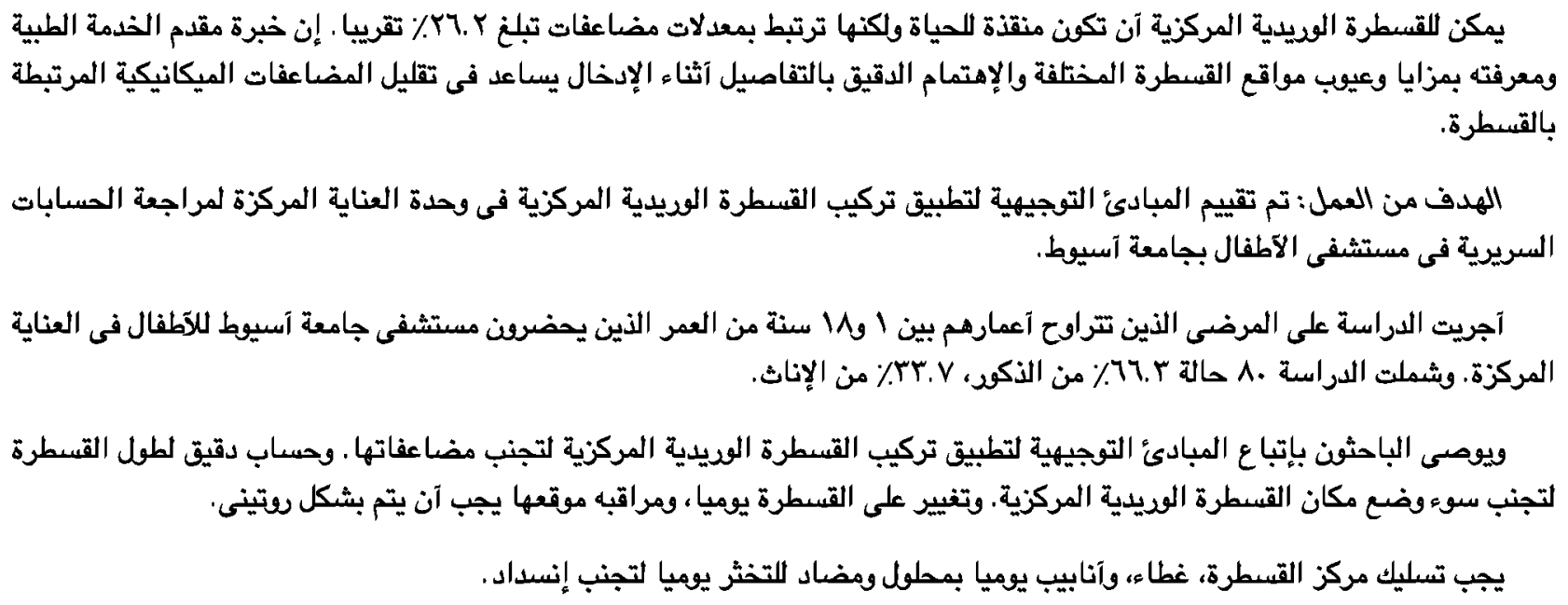

